Check for updates

Cite this: RSC Adv., 2018, 8, 36430

\title{
Preparation and characterization of a novel nanofiltration membrane with chlorine-tolerant property and good separation performance
}

\author{
Yi Liu, (D) ab Bo Lin, ${ }^{\text {ab }}$ Wenchao Liu, ${ }^{\mathrm{b}}$ Junjun Li, ${ }^{\mathrm{b}}$ Congjie Gao*bc and Qiaoming Pan*b
}

High water flux, good separation property and excellent chlorine resistance are crucial factors affecting the development of nanofiltration (NF) membranes. To obtain these properties, NF membranes were fabricated via interfacial polymerization using $m$-xylylenediamine ( $m$-XDA) and polyethyleneimine (PEI) as aqueous monomers. By controlling the concentration ratio of $m-X D A$ and $P E I$ in the aqueous solution, it was found that the addition of $\mathrm{PEI}$ to the aqueous solution can increase the rejection of the NF membrane to magnesium chloride $\left(\mathrm{MgCl}_{2}\right)$ and magnesium sulfate $\left(\mathrm{MgSO}_{4}\right)$ from $18.3 \%, 54.5 \%$ to $84.4 \%, 94.1 \%$, respectively. Meanwhile, the rejection to sodium sulphate $\left(\mathrm{Na}_{2} \mathrm{SO}_{4}\right)$ and sodium chloride $(\mathrm{NaCl})$ remain essentially unchanged. On the other hand, the addition of $m$-XDA to the aqueous solution can improve the chlorine resistance of the NF membrane, but it decreased the water flux of NF membrane. Sodium hypochlorite $(\mathrm{NaClO})$ solution was used to evaluate chlorine resistance of NF membranes. After 10000 ppm $\mathrm{h} \mathrm{NaClO}$ immersion, the rejections to $\mathrm{Na}_{2} \mathrm{SO}_{4}$ of $\mathrm{NF}$ membranes prepared from the pure $m-\mathrm{XDA}$ and the blend of $m-X D A$ and PEI were basically unchanged and the water flux increased. In conclusion, the obtained membranes not only exhibited good separation performance but also had good chlorine resistance.

Received 5th September 2018 Accepted 16th October 2018

DOI: $10.1039 / c 8 r a 06755 d$

rsc.li/rsc-advances carrying numerous primary and secondary amine groups, began to be widely used in fabricating NF membranes that can reject multivalent cations effectively. Nan Q. et al. fabricated a positively charged NF membrane via the layer-by-layer assembly of graphene oxide and PEI, the best performance can be achieved with salt rejection of $93.9 \%$ and $38.1 \%$ for $\mathrm{Mg}^{2+}$ and $\mathrm{Na}^{+}$, and a water flux of $42 \mathrm{~L} \mathrm{~m}^{-2} \mathrm{~h}^{-1} \cdot{ }^{12}$ A positively charged NF membrane with high rejection to divalent metal ion was fabricated via IP using PEI as the aqueous precursor by Zhang et al., and then modified hydroxyl containing multiwalled carbon nanotubes (MWCNTs-OH) were used to improve membrane performance by grafting with piperazine (PIP). ${ }^{13}$ Anupam Bera et al. proposed a method to fabricate NF membrane by using PEI-Dex as a new monomer or comonomer for IP with trimesoyl chloride (TMC), and the prepared membrane can exhibit good $\mathrm{Na}^{+} / \mathrm{Mg}^{2+}$ selectivity. ${ }^{14}$

As indicated above, the NF membranes prepared from PEI exhibit good separation performance, but the membrane oxidation is still a unavoidable drawback that restricts the development of these NF membranes. ${ }^{15,16}$ Free chlorine is commonly used as disinfectant to kill bacteria during the pretreatment of the raw water. Once it contacts with polyamide (PA) NF membranes, a drastic decrease in membrane performance will occur. ${ }^{17}$ In the last few years, lots of efforts have been tried to improve the chlorine resistance of PA NF membranes. Lin et al. used a facile two-step surface modification to fabricate PA composite membranes with good chlorine resistance 
simultaneously possessing good separation property. ${ }^{18} \mathrm{Hu}$ et al. synthesized a new amine monomer-BHTTM for fabricating highly productive chlorine-tolerant NF membrane by IP. ${ }^{19}$ Zhang et al. prepared NF membrane via IP using PIP and BHTTM as aqueous monomers, TMC as organic monomer, and the water flux and rejection to $\mathrm{Na}_{2} \mathrm{SO}_{4}$ of the prepared $\mathrm{NF}$ membrane are maintain at $51.6 \mathrm{~L} \mathrm{~m}^{-2} \mathrm{~h}^{-1}$ and $99.6 \%$ after chlorination treatment. ${ }^{20}$

Mixing different amine monomers is an effective and practical way to fabricate NF membranes with high performance. ${ }^{21-23}$ In this study, we selected the blend of $m$-xylylenediamine $(m-\mathrm{XDA})$ and PEI as aqueous co-monomer reacted with TMC to prepare NF membrane by IP (see Fig. 1). There is a methylene between amine group and benzene ring in molecular structure of $m$-XDA which can reduce the activity of amide bonds to improve its chlorine resistance. Furthermore, it can increase the steric hindrance and make Orton rearrangement less likely to occur to further enhance its chlorine resistance. ${ }^{24,25}$ As mentioned above, the NF membrane prepared from PEI has good separation performance but poor chlorine resistance. In addition, it must be mentioned that $m$ XDA-based membrane is commonly negatively charged while PEI-based membrane is positively charged ${ }^{26}$ Therefore, it's desirable to utilize the differences in diffusion and reactivity between $m$-XDA and PEI, combined with their advantages to optimize the performance of the prepared NF membrane. The effect of the concentration ratio of $m$-XDA and PEI on the performance of NF membrane was systematically studied. The chemical composition, hydrophilicity, surface charge and morphology of the NF membranes were characterized by ATRFTIR, XPS, water contact angle, zeta potential measurements, SEM and AFM, respectively.<smiles>CCCN(CCN)CCNCCN(CCNCCN)CCN(CCN)CCNCCN</smiles>

PEI and $\mathrm{m}-\mathrm{XDA}$<smiles>NCc1cccc(CN)c1</smiles>

Interfacial polymerization<smiles>O=C(Cl)c1cc(C(=O)Cl)cc(C(=O)Cl)c1</smiles>

TMC

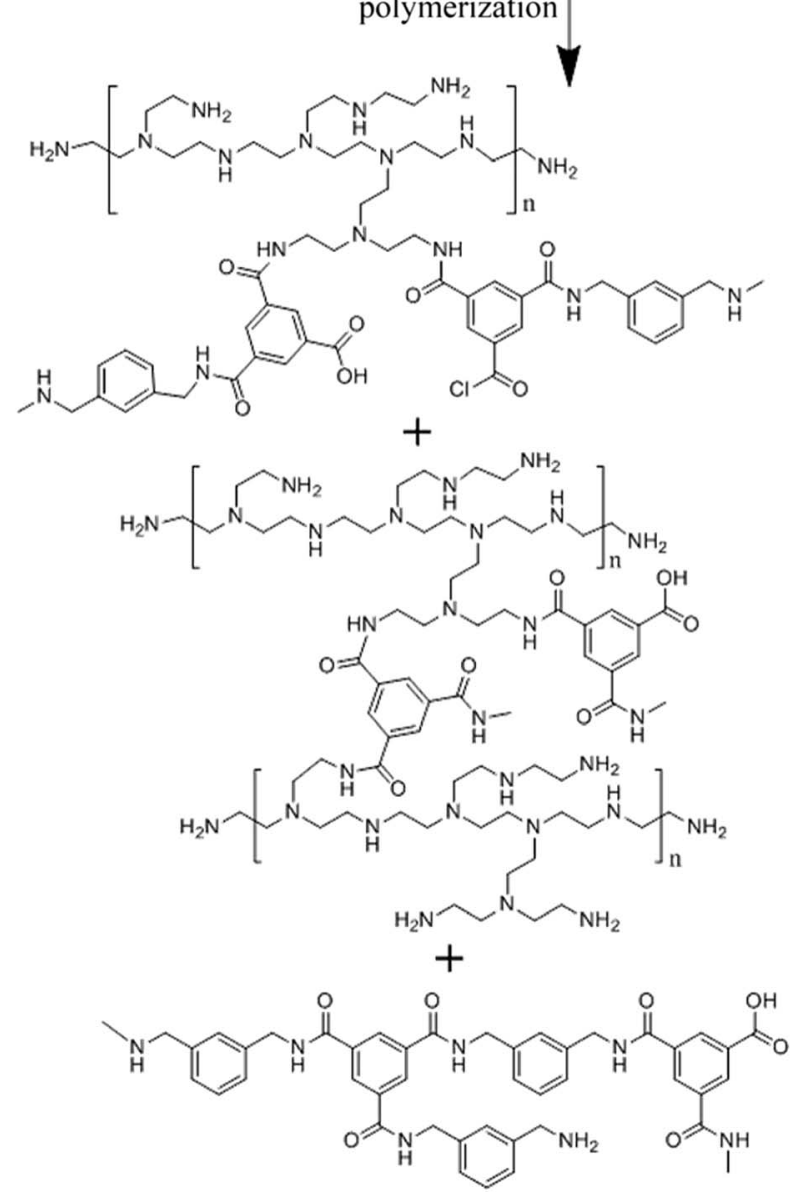

Fig. 1 Polymerization reaction for fabricating NF membrane based on $m$-XDA/PEI and TMC. 


\section{Experimental}

\subsection{Materials}

The commercial polyether sulfone (PES) UF membrane used as the support membrane was provided by Hangzhou Water Treatment Technology Development Center (China). The support membrane with a molecular weight cut-off of approximately 20000 dalton had a water permeability of $200 \mathrm{~L} \mathrm{~m}^{-2}$ $\mathrm{bar}^{-1}$. Tetraethylammonium chloride (TEAC, $\geq 98 \%$ ) as a surfactant was purchased from Shanghai Macklin Biochemical Co., Ltd. The inorganic salts including $\mathrm{Na}_{3} \mathrm{PO}_{4} \cdot 12 \mathrm{H}_{2} \mathrm{O}$, $\mathrm{NaCl}, \mathrm{MgCl}_{2} \cdot 6 \mathrm{H}_{2} \mathrm{O}, \mathrm{Na}_{2} \mathrm{SO}_{4}$ and $\mathrm{MgSO}_{4}$ are provided from Hangzhou Lanbo Industrial Co., Ltd. Other reagents and chemicals were purchased from Aladdin Industrial Corporation, including $m$-xylylenediamine ( $m$-XDA), branched polyethyleneimine (PEI, MW $=2500 \mathrm{Da}$ ) and sodium hypochlorite solution (NaClO, $5.5 \mathrm{wt} \%$ active chlorine). Trimesoyl chloride (TMC, $\geq 98 \%$ ) was purchased from Qingdao Benzo Chemical Co., China. Isopar L as organic solvent was purchased from Exxon Mobil company. The deionized (DI) water obtained by electrodialysis of reverse osmosis water was used for all experiment.

\subsection{Preparation of NF membrane}

The PES UF membrane was fixed with epoxy resin frame, washed with DI water and immersed in DI water. The aqueous phase solution was obtained by dissolving $m$-XDA and PEI in DI water, the total concentration of $m$-XDA and PEI was kept at $0.1 \mathrm{wt} \%$ while the concentration ratio of $m$-XDA and PEI varied from $1: 0,4: 1,3: 2,2: 3,1: 4$ to $0: 1$, and then added TEAC and $\mathrm{Na}_{3} \mathrm{PO}_{4}$ as surfactant and buffer. The organic phase was an isopar L solution containing $0.1 \mathrm{wt} \%$ TMC. The IP process is as follows: firstly, the aqueous phase solution was poured onto the PES UF film for $60 \mathrm{~s}$, and the excess water is removed by the squeeze roller; then, the organic phase solution was poured onto the base film and kept contact for $30 \mathrm{~s}$; next, the membrane placed in a blast oven at $80{ }^{\circ} \mathrm{C}$ for $10 \mathrm{~min}$; finally, the obtained composite NF membrane was washed with DI water and soaked in DI water for use. The PES UF membrane is denoted as M0, and PA NF membranes prepared by amine solution containing the concentration ratio of $m$-XDA and PEI are $1: 0,4: 1,3: 2,2: 3,1: 4$ and $0: 1$ labeled as M1, M2, M3, M4, M5 and M6, respectively.

\subsection{Membrane characterization}

The functional structure of NF membrane surface was examined by Attenuated Total Reflection Fourier Transform Infrared Spectroscopy (ATR-FTIR, Nicolet 6700). For ATR-FTIR analysis of the membrane samples, the resulting NF membranes were vacuum dried $\left(50^{\circ} \mathrm{C}, 12 \mathrm{~h}\right)$ and characterized by total reflection of zinc selenide crystal. The chemical compositions of the NF membrane were measured by X-ray photoelectron spectroscopy (XPS, Kratos AXIS Ultra DLD). In order to increase the reliability of the experiment, each sample was characterized 3 times.

The static water contact angle was measured on a dried membrane surface by a contact angle analyzer (OCA-20,
Germany) at ambient temperature. After each drop, image was captured and the reading was recorded. For each sample, at least 12 readings were obtained, and the average contact angle values were calculated from these readings.

Zeta potentials of membrane samples were measured by SurPASS analyzer (Anton Paar, Austria). The $0.001 \mathrm{~mol} \mathrm{~L}^{-1} \mathrm{KCl}$ was used as the test solution, and the $\mathrm{pH}$ value was adjusted by $\mathrm{KOH}$ and $\mathrm{HCl}$ solution to investigate the effect of $\mathrm{pH}$ on the zeta potential.

The morphologies of the NF membrane surface were observed by scanning electron microscopy (SEM, Hitachi S4700). The prepared NF membrane was vacuum dried $\left(50{ }^{\circ} \mathrm{C}\right.$, $12 \mathrm{~h}$ ), then the surface of the membrane were scanned after coating with gold. The NF membrane surface roughness was obtained by atomic force microscopy (AFM, XE-100) with $5 \mu \mathrm{m}$ $\times 5 \mu \mathrm{m}$ scanning range. RMS means the root mean square roughness, and $R_{\mathrm{a}}$ means the arithmetic mean roughness.

\subsection{Treatment of NF membrane with chlorine solution}

Both free chlorine concentration and exposure time have effect on the membrane performance. ${ }^{27}$ Herein, the free chlorine concentration of solutions was set at $500 \mathrm{ppm}$ and adjusted the $\mathrm{pH}$ value of solution to 4.0 by $\mathrm{HCl}$. Membrane samples were immersed into the NaClO solution for various times varied from $1 \mathrm{~h}$ to $20 \mathrm{~h}$. The chlorination tests were carried out in Pyrex bottles at room temperature to prevent free chlorine degradation. Took out the membrane samples when the time is up. After thoroughly rinsing the membranes with DI water, tested the performance of the membrane samples.

\subsection{Membrane experimental procedures}

All experiments that evaluated the performance of the NF membranes were performed by cross-flow filtration. Test conditions are as follows: the operating pressure and temperature are $1.0 \mathrm{MPa}$ and $25{ }^{\circ} \mathrm{C}$, respectively; the concentrations of $\mathrm{Na}_{2} \mathrm{SO}_{4}, \mathrm{NaCl}, \mathrm{MgSO}_{4}$ and $\mathrm{MgCl}_{2}$ feed solutions were kept at $2000 \mathrm{ppm}$ and adjusted the $\mathrm{pH}$ value to 7. Before evaluation, the membranes were pre-filtrated for $1 \mathrm{~h}$ at $1.0 \mathrm{MPa}$ to reach a steady state. The water flux $\left(\mathrm{L} \mathrm{m}^{-2} \mathrm{~h}^{-1}\right)$ was calculated by eqn (1):

$$
J=\Delta V /(S \times \Delta t)
$$

where $\Delta V(\mathrm{~L})$ is the volume of permeate solution, $S\left(\mathrm{~m}^{2}\right)$ is the effective membrane area (i.e. $12.2 \mathrm{~cm}^{2}$ ), $t(\mathrm{~h})$ is the test time.

The salt rejection (\%) was calculated from eqn (2):

$$
R=\left(1-\left(C_{\mathrm{p}} / C_{\mathrm{f}}\right)\right) / 100 \%
$$

where $R$ is salt rejection, $C_{\mathrm{p}}$ and $C_{\mathrm{f}}$ are the concentrations of permeate and feed solution, respectively.

The $\mathrm{Na}^{+} / \mathrm{Mg}^{2+}$ selectivity was calculated using eqn (3):

$$
\alpha=\left(100-R^{\mathrm{NaCl}}\right) /\left(100-R^{\mathrm{MgCl}_{2}}\right) \times 100 \%
$$

where $\alpha$ is the $\mathrm{Na}^{+} / \mathrm{Mg}^{2+}$ selectivity, $R^{\mathrm{NaCl}}$ and $R^{\mathrm{MgCl}_{2}}$ are the rejection to $\mathrm{NaCl}$ and $\mathrm{MgCl}_{2} \cdot{ }^{12}$ 

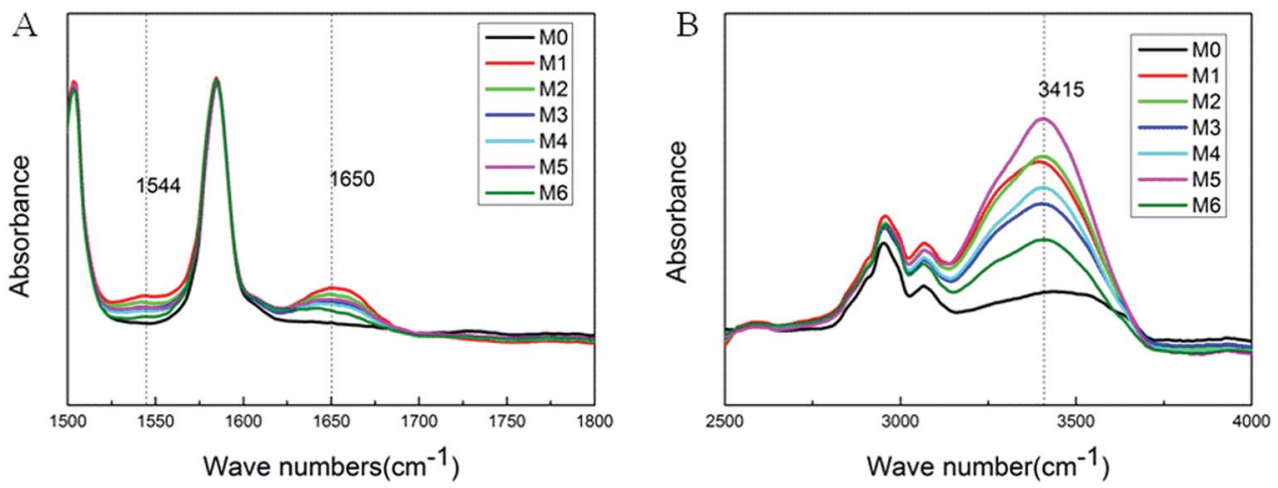

Fig. 2 ATR-FTIR spectra of the M0, M1, M2, M3, M4, M5 and M6.

\section{Results and discussion}

\subsection{The chemical composition on the NF membrane surface}

ATR-FTIR is used to characterize the chemical structure of NF membrane. The Fig. 2 shows the ATR-FTIR spectra of M0, M1, M2, M3, M4, M5 and M6, respectively. And the absorption peak of the phenyl ether group (Ar-O-Ar, $1240 \mathrm{~cm}^{-1}$ ) on the M0 was selected as an internal standard, all spectra were normalized. ${ }^{28,29}$ Compared to the M0, two new absorption peaks at about $1544 \mathrm{~cm}^{-1}$ and $1650 \mathrm{~cm}^{-1}$ appeared on the spectra of M1, M2, M3, M4, M5 and M6, which are related to the characteristic peaks of the amide-II $(\mathrm{N}-\mathrm{H})$ band and amide-I $(\mathrm{C}=\mathrm{O})$ band of the amide groups (-CO-NH-) (see Fig. 2A). It means that the surface of the support membrane does form a PA layer after the IP process. Moreover, a new absorption band was observed at about $3415 \mathrm{~cm}^{-1}$ which is ascribed to the absorption of $-\mathrm{NH}$ that unreacted and the absorption of $-\mathrm{OH}$ in residual carboxyl groups (see Fig. 2B). By comparing the absorption intensity of these peaks on the spectra of various NF membrane, it can be found that the intensities of the amide groups decrease with the increasing proportion of PEI in total amines. Consequently, it can be implied that the higher proportion of PEI in total amines, the lower crosslinking degree of NF membrane surface.

XPS can be used for quantitative analysis of element composition for the top 1-5 nm depth of the skin layer. The intensity of photoelectron line (area of the photoelectron peak) in the energy spectrum can reflect the atomic content. ${ }^{30}$ Herein, the sensitivity factors of $\mathrm{N} 1 \mathrm{~s}$ and $\mathrm{O} 1 \mathrm{~s}$ used to calculate surface composition are 0.477 and 0.780 , respectively. Table 1 lists the elemental contents and $\mathrm{O} / \mathrm{N}$ value of M1, M2, M3, M4, M5 and M6. Many researchers have used the $\mathrm{O} / \mathrm{N}$ atomic ratio to estimate the degree of cross-linking of PA skin layer. ${ }^{31}$ In theoretically, the $\mathrm{O} / \mathrm{N}$ atomic ratio of a fully linear structure is 2 while the $\mathrm{O} / \mathrm{N}$ value is 1 for a fully cross-linked PA layer. ${ }^{32}$ As shown in Table 1 , the $\mathrm{O} / \mathrm{N}$ value of $\mathrm{M} 0$ is 1.09 as near as the theoretical value for fully cross-linked skin layer. By contrast, the $\mathrm{O} / \mathrm{N}$ value of M6 is 1.34 which can be inferred that there are more linear structures formed in PA functional layer. This means that the increase in the proportion of PEI in the total amines reduces the degree of cross-linking of PA skin layer. Due to the low reactivity and mobility in the organic phase, it's difficult for PEI to further
Table 1 Elemental contents and O/N ratio of the M1, M2, M3, M4, M5 and M6

\begin{tabular}{lllll}
\hline & \multicolumn{2}{l}{ Atomic percent $(\%)$} & \\
\cline { 2 - 4 } Membrane & $\mathrm{C}$ & $\mathrm{O}$ & $\mathrm{N}$ & $\mathrm{O} / \mathrm{N}$ atomic ratio \\
\hline M1 & $73.5 \pm 2.4$ & $13.8 \pm 0.8$ & $12.7 \pm 0.9$ & 1.09 \\
M2 & $73.3 \pm 1.5$ & $14.2 \pm 0.9$ & $12.5 \pm 0.6$ & 1.14 \\
M3 & $73.0 \pm 1.1$ & $14.6 \pm 0.4$ & $12.4 \pm 0.7$ & 1.18 \\
M4 & $72.8 \pm 1.0$ & $14.9 \pm 0.5$ & $12.3 \pm 0.6$ & 1.21 \\
M5 & $72.6 \pm 0.6$ & $15.1 \pm 0.2$ & $12.3 \pm 0.8$ & 1.23 \\
M6 & $71.9 \pm 0.4$ & $16.1 \pm 0.2$ & $12.0 \pm 0.4$ & 1.34
\end{tabular}

react with TMC across the nascent membrane. The gentle IP reaction between PEI and TMC generates more carboxylic groups resulting from the hydrolysis of residual acyl chlorine groups on the membrane surface. ${ }^{20}$ These hydrophilic hydroxyl groups and carboxyl groups not only increase the oxygen atom content but also increase the hydrophilicity of the membrane surface.

\subsection{Surface hydrophilicity of NF membrane}

The membrane surface hydrophilicity was evaluated by static water contact angle and the results are depicted in Fig. 3. It can be clearly known that the Mo has a water contact angle of $81.5^{\circ}$

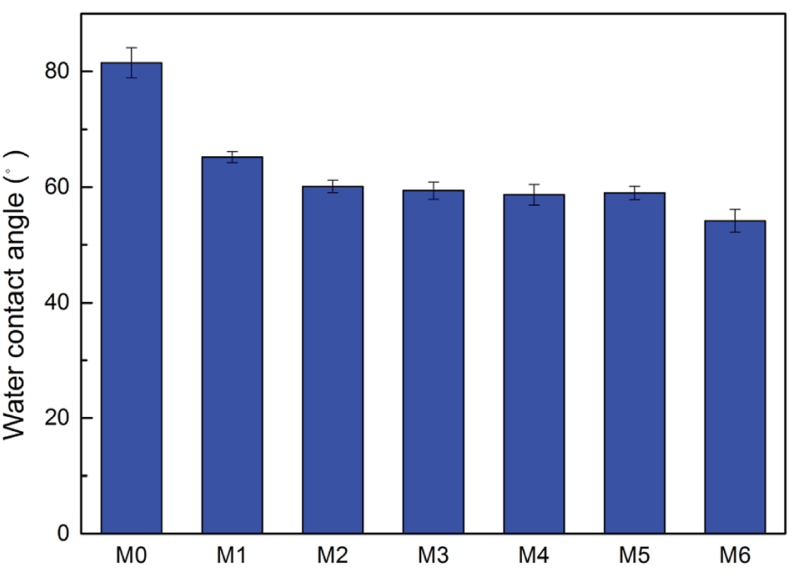

Fig. 3 Water contact angles of M0, M1, M2, M3, M4, M5 and M6. 
and the water contact angle decreases after fabricating a PA skin layer on the PES support membrane. To be specific, the water contact angle of M1, M2, M3, M4, M5 and M6 are $65.2^{\circ}, 60.1^{\circ}$, $59.4^{\circ}, 58.7^{\circ}, 59^{\circ}$ and $54.2^{\circ}$, respectively, which showed a clear downward trend. Generally, a lower water contact angle suggests that the membrane surface is more hydrophilic. In other words, the decreasing trend indicates that membrane surface hydrophilicity increases with the increase of PEI content in total amines. In fact, membrane surface hydrophilicity is commonly attributed to the chemical composition and the surface morphology. ${ }^{33}$ According to the ATR-FTIR and XPS results, hydrophilic groups are introduced into the PA skin layer resulting in a significant improvement in the hydrophilicity of NF membranes. And there will be more hydrophilic groups on the NF membrane surface when the ratio of PEI in total amines increases, so the hydrophilicity of the NF membrane further increases. In summary, the addition of PEI into aqueous phase leads to a more hydrophilic surface which is beneficial to improve the water flux. ${ }^{34}$

\subsection{Surface charge of NF membrane}

The surface charge of four NF membranes were studied in terms of zeta potential at $\mathrm{pH}$ ranging from 3 to 11 . At $\mathrm{pH}$ above the isoelectric point, the presence of carboxyl groups leads to a negative membrane surface, whereas membrane surface possess positive charges at $\mathrm{pH}$ below the isoelectric point due to protonation of the amine groups. ${ }^{35}$ As illustrated in Fig. 4, the M1 prepared from pure $m$-XDA has an isoelectric point of 4.14 which is obviously negatively charged at the testing condition. Correspondingly, the membrane M6 prepared from pure PEI has a relatively high isoelectric point of 4.71 and is also negatively charged. When the proportion of PEI in total aminess increases, the isoelectric point of M2, M3, M4, M5 and M6 gradually move to higher $\mathrm{pH}$ value in sequence. This is mainly attributed to more amine groups unreacted, and the protonation of amine groups leads to more positively charged on the NF membrane surface. But on the other side, the gentle reaction between PEI and TMC generates more residual acyl chlorine

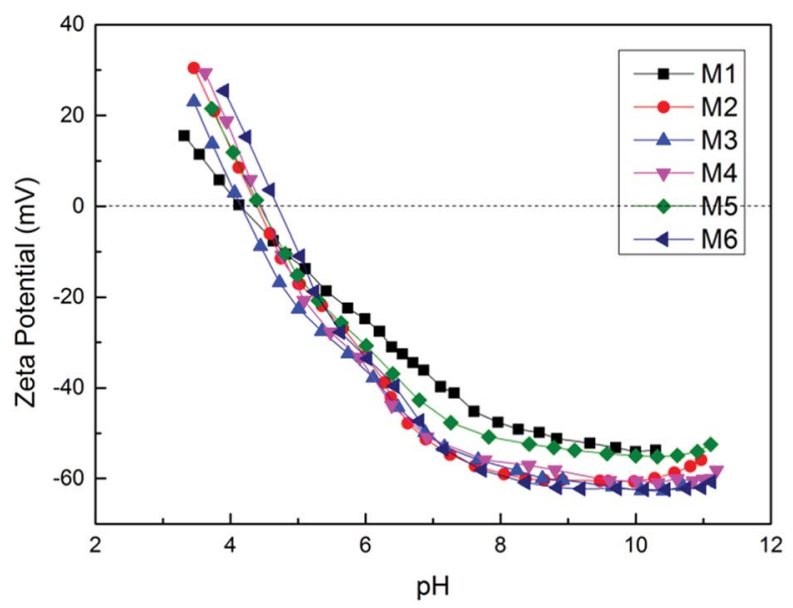

Fig. 4 Zeta potential of various NF membranes. groups resulting in more negatively charged on the NF membrane surface. ${ }^{20}$ The two competing processes make membrane surface keep negatively charged all the time. Nevertheless, it still caused the isoelectric point move to higher $\mathrm{pH}$ value. In addition, because the number of amine and carboxyl groups increased, the absolute value of surface charged increased. ${ }^{36}$

\subsection{Surface morphology of NF membrane}

SEM and AFM can be used to analyze the surface morphology and roughness of the NF membrane. The SEM images of the surface morphology of 7 membrane samples and cross-section images of M1 and M6 are shown in Fig. 5. As can be seen from Fig. $5 \mathrm{H}$ and $\mathrm{I}$, the thickness of the PA layer is above $100 \mathrm{~nm}$. It can be clearly seen from Fig. 5A that there are many visible needle-shaped pores on the surface of the PES substrate membrane. In the Fig. 5G, it's still observed that the smaller pores on the surface of the M6 coexisted with the crack after IP reaction between pure PEI and TMC. When the aqueous phase contains PEI and $m$-XDA, the needle-shaped pores are completely disappeared and are replaced by many dendritic cracks in Fig. 5B-F. This can be speculated that the surfaces of M1, M2, M3, M4, M5 and M6 form an ultra-thin dense layer which indicates that M1, M2, M3, M4, M5 and M6 have successfully prepared a PA functional layer on PES substrate membrane by IP. Most studies believe that the IP reaction takes place on the side of the organic phase..$^{37,38}$ Therefore, the IP reaction can be imagined as a process in which the aqueous monomer diffuses to the organic phase and reacts with the acid chloride to form a polyamide network to inhibit self-diffusion. ${ }^{39}$ When $m$-XDA and PEI monomers are added into the aqueous phase, the difference in diffusion rate between the two monomers determines the distribution of these in the functional layer to some extent. Because of higher diffusion rate of $m$-XDA, the top surface of the functional layer is mainly $m$-XDA-TMC cross-links which are more dense than PEI-TMC cross-links. So it can be found that the membrane surface of M1, M2, M3, M4 and M5 are relatively compact by comparing with M6.

Fig. 6 represents AFM three-dimensional images of M0, M1, M2, M3, M4, M5 and M6, the RMS and $R_{\mathrm{a}}$ values used to evaluate membrane surface roughness are listed in Table 2. As shown in Table 2, the RMS of M0, M1, M2, M3, M4, M5 and M6 are $4.2,18.9,12.8,11.3,10.2,8.5$ and 5.8, respectively. By comparing with the support film M0, it can be found that the surface roughness of the NF membranes increases after the IP reaction. Moreover, membrane surface roughness decreases with the increasing proportion of PEI in total amines. The corresponding topological characteristics can be seen in Fig. 6. In the Fig. $6 \mathrm{~A}, \mathrm{~F}$ and $\mathrm{G}$, it can be seen that a large number of pointed conical structures densely distributed on the membrane surface. In the Fig. 6B-E, some small nodules start to appear on the membrane surface and the $R_{\mathrm{a}}$ values are 10.4, 7.2, 6.1 and 5.3, respectively, with a significant downward trend. Because of the macromolecular structure of PEI, the IP reaction rate between PEI and TMC is slower than that between $m$-XDA and TMC, so the formation of the PA layer is easily controlled, 

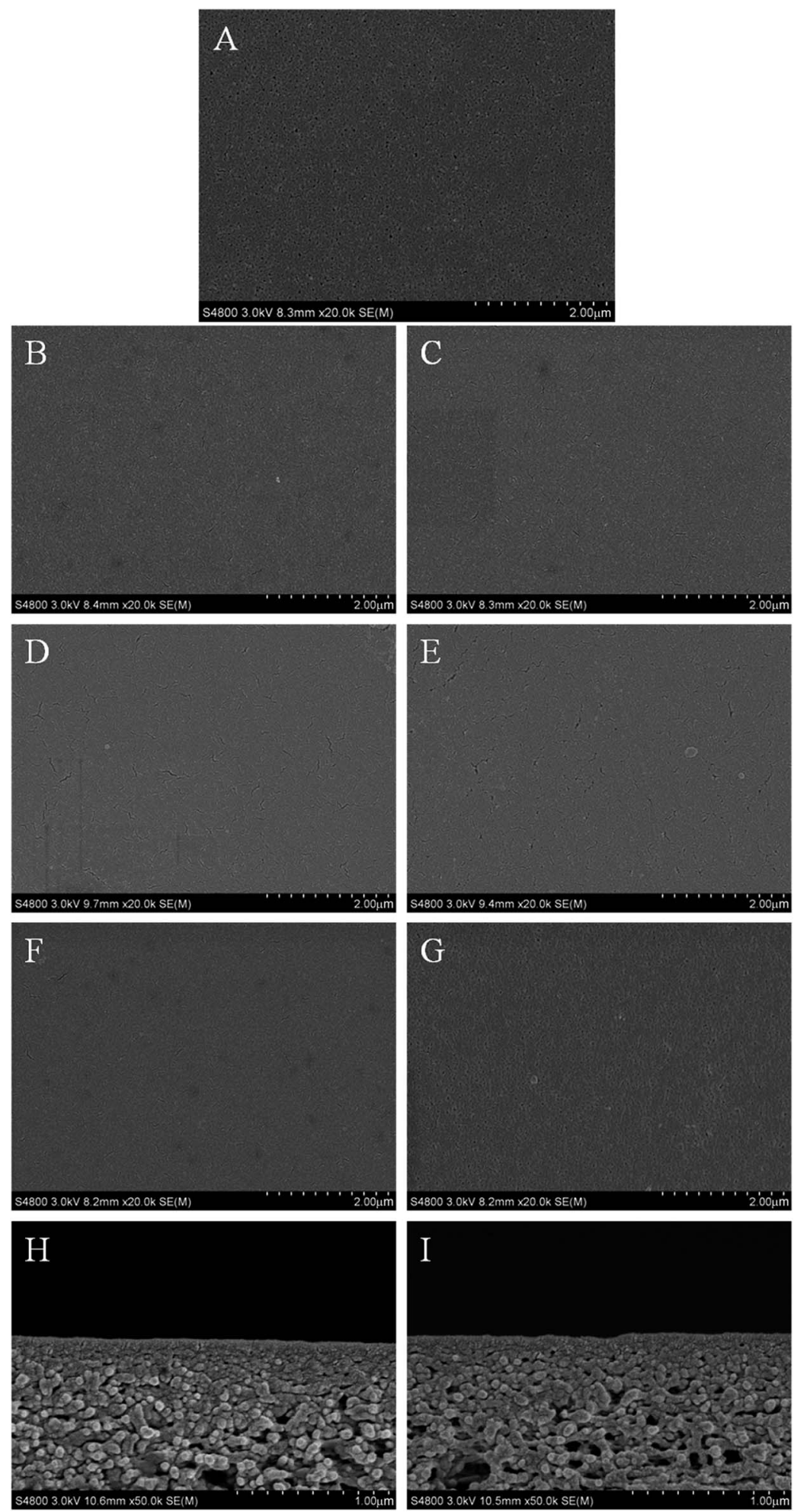

Fig. 5 SEM surface images of M0 (A), M1 (B), M2 (C), M3 (D), M4 (E), M5 (F), M6 (G) and cross-section images of M1 (H), M6 (I).

thereby making the PA skin layer relatively smooth. When $m$ XDA content in total amines is high enough, more rapid formation of $m$-XDA-TMC cross-links has a significant effect on slow cross-linking between the PEI and TMC. As a result, M1, M2, M3 and M4 have a rough surface with nodules.

\subsection{Effect of $m$-XDA/PEI ratio on the NF membrane performance}

The effect of $m$-XDA/PEI concentration ratio on the desalination performance of NF membrane is shown in Fig. 7. It was clearly seen that as the proportion of PEI in total amines 

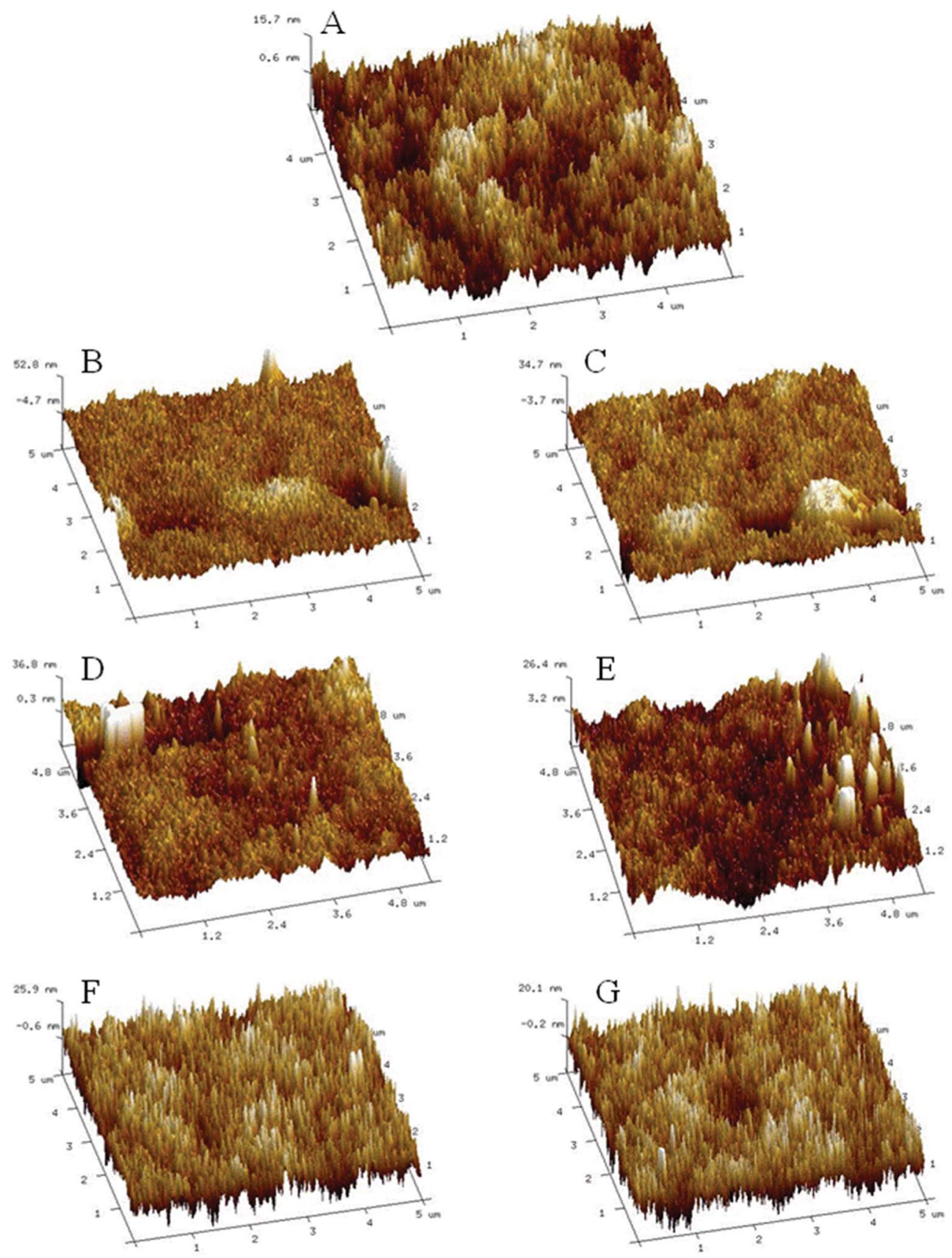

Fig. 6 AFM three-dimensional images of M0 (A), M1 (B), M2 (C), M3 (D), M4 (E), M5 (F) and M6 (G).

Table 2 Roughness values of M0, M1, M2, M3, M4, M5 and M6

\begin{tabular}{lcc}
\hline Membrane & RMS $(\mathrm{nm})$ & $R_{\mathrm{a}}(\mathrm{nm})$ \\
\hline M0 & 4.2 & 3.1 \\
M1 & 18.9 & 10.4 \\
M2 & 12.8 & 7.2 \\
M3 & 11.3 & 6.1 \\
M4 & 10.2 & 5.3 \\
M5 & 8.5 & 5.1 \\
M6 & 5.8 & 4.0
\end{tabular}

increases, the water flux of NF membrane increases. When the concentration ratio of $m$-XDA and PEI changed from $1: 0$ to $0: 1$, the water flux increases from $39 \mathrm{~L} \mathrm{~m}^{-2} \mathrm{~h}^{-1}$ to $89 \mathrm{~L} \mathrm{~m}^{-2}$ $\mathrm{h}^{-1}$. It is worth noting that the rejections to $\mathrm{NaCl}$ and $\mathrm{Na}_{2} \mathrm{SO}_{4}$ remain essentially unchanged no matter how the concentration ratio of $m$-XDA and PEI changes, as shown in Fig. 7A and B. However, the concentration ratio of $m$-XDA and PEI has greater effect on the rejections to $\mathrm{MgCl}_{2}$ and $\mathrm{MgSO}_{4}$. As given in Fig. $7 \mathrm{C}$ and $\mathrm{D}$, the rejection to $\mathrm{MgSO}_{4}$ and $\mathrm{MgCl}_{2}$ of $\mathrm{NF}$ membranes gradually increase from $54.5 \%, 18.3 \%$ to $94.1 \%$, $84.4 \%$, respectively. As mentioned previously, with a mixture of $m$-XDA and PEI, the top surface of PA functional layer will be 

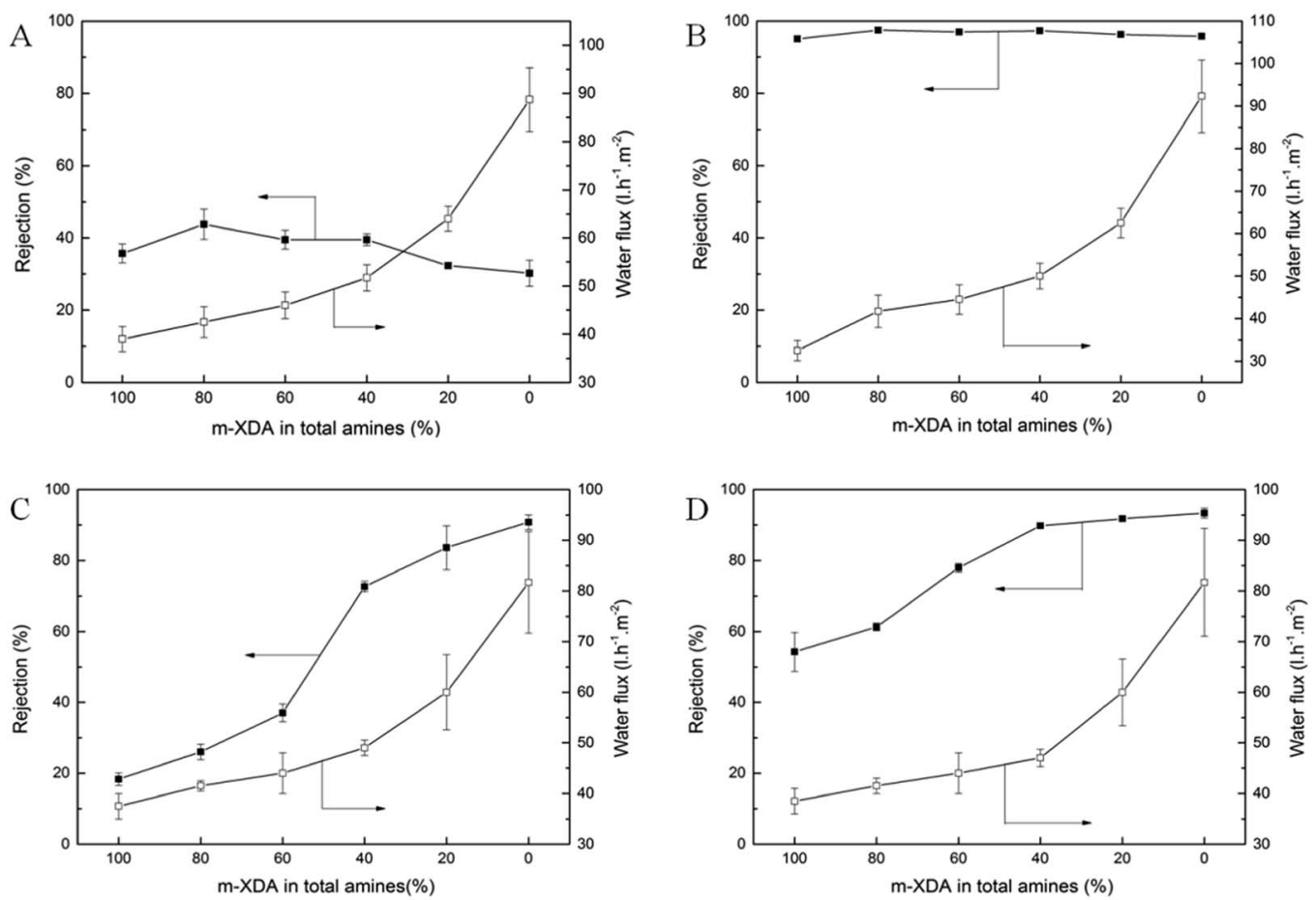

Fig. 7 Separation performance of the various $\mathrm{NF}$ membrane to $\mathrm{NaCl}(\mathrm{A}), \mathrm{Na}_{2} \mathrm{SO}_{4}$ (B), $\mathrm{MgCl}_{2}$ (C) and $\mathrm{MgSO}_{4}$ (D).

dominated by $m$-XDA-TMC cross-links which are more dense than PEI-TMC cross-links. There is no doubt that the decreased proportion of $m$-XDA in total amines will result in low crosslinking degree of produced PA skin layer. The increase of hydrophilicity and decrease in cross-linking degree effectively improve the water flux from $39 \mathrm{~L} \mathrm{~m}^{-2} \mathrm{~h}^{-1}$ to $89 \mathrm{~L}$ $\mathrm{m}^{-2} \mathrm{~h}^{-1}$. It's well known that the main factors affecting salt rejection are steric hindrance and Donnan effect. ${ }^{40,41} \mathrm{~A}$ high PEI concentration makes for a low degree of cross-linking which reduces the steric hindrance, thereby reducing the rejection to inorganic salts and increasing the water flux. And there are a greater number of unreacted amine groups that can generate more positive charges inside the PA functional layer so that the rejection to multivalent cations of NF membrane increases. Since monovalent ions such as $\mathrm{Na}^{+}$and $\mathrm{Cl}^{-}$have a weak electrostatic repulsion, the steric hindrance has a greater impact on the rejection to $\mathrm{NaCl}$. The effect of the Donnan exclusion on the rejection of multivalent ions is more pronounced. So the rejection to $\mathrm{NaCl}$ decreases slightly and the rejection to $\mathrm{MgSO}_{4}$ and $\mathrm{MgCl}_{2}$ keep increased when PEI was added into aqueous phase.

Compared to the $\mathrm{Na}^{+} / \mathrm{Mg}^{2+}$ selectivity of M1, M2, M3, M4, M5 and M6 as listed in Table 3, the higher proportion of PEI in total amines, the larger $\alpha$ value. This is ascribed to the stronger positive charge in NF membrane in accordance with zeta potential in Section 3.4. So the NF membrane has a good $\mathrm{Na}^{+}$/ $\mathrm{Mg}^{2+}$ selectivity when the PEI content is high enough. It can be concluded that NF membrane with high separation performance could be obtained by controlling the concentration ratio of $m$-XDA and PEI.

\subsection{Chlorine tolerance of NF membrane}

Fig. 8 shows the effects of chlorination time on the performance of four NF membranes. It can be seen from Fig. 8A that the rejection to $\mathrm{Na}_{2} \mathrm{SO}_{4}$ of M1, M2 and M5 suffered a slight decline after soaking in $\mathrm{NaClO}$ solution. And a rapid decline of rejection to $\mathrm{Na}_{2} \mathrm{SO}_{4}$ appeared in $\mathrm{M} 6$. When the soaking time reaches $20 \mathrm{~h}$, the rejection to $\mathrm{Na}_{2} \mathrm{SO}_{4}$ of $\mathrm{M} 6$ drops from $95.8 \%$ to $34.3 \%$. Relatively speaking, the M1 prepared from pure $m$-XDA has good chlorine resistance. Even if the soaking time reaches $20 \mathrm{~h}$, the rejection to $\mathrm{Na}_{2} \mathrm{SO}_{4}$ of M1 doesn't change obviously. More important is that the prepared NF membrane still has relatively good chlorine resistance when the concentration ratio of $\mathrm{m}^{-}$ $\mathrm{XDA} / \mathrm{PEI}$ in aqueous solution is $1: 4$. What's more, it can be found in Fig. 8B that the water flux of M1, M2, M5 and M6 increased after the NF membranes were immersed in the NaClO solution, but the water flux growth rate of other NF membranes were slower than that of M6. In conclusion, by adding a small amount of $m$-XDA to the amine solution, the chlorine resistance of the prepared NF membrane can be significantly increased.

When the dominant component in NaClO solution is hypochlorous acid, most researchers divided the chlorination process of the aromatic PA NF membrane into two stages as follow: the first stage is the N-chlorination of the amide bond, second stage is ring chlorination through Orton-rearrangement. ${ }^{42}$ Under acidic condition, $\mathrm{N}$-chlorination and the following ring chlorination can destroy intermolecular hydrogen bonds and disrupt the symmetry of the PA network. ${ }^{43}$ And then the NF membrane has a rapid decline in the rejection to inorganic salts owing to the conformational deformation of the polymer chain. ${ }^{16}$ Meanwhile, on account of the compaction 
Table 3 The $\mathrm{Na}^{+} / \mathrm{Mg}^{2+}$ selectivity of $\mathrm{M} 1, \mathrm{M} 2, \mathrm{M} 3, \mathrm{M} 4, \mathrm{M} 5$ and M6

\begin{tabular}{|c|c|c|c|c|c|}
\hline Membrane & $R_{\mathrm{NaCl}}(\%)$ & $J_{\mathrm{NaCl}}\left(\mathrm{L} \mathrm{m}^{-2} \mathrm{~h}^{-1}\right)$ & $R_{\mathrm{MgCl}_{2}}(\%)$ & $J_{\mathrm{MgCl}_{2}}\left(\mathrm{~L} \mathrm{~m}^{-2} \mathrm{~h}^{-1}\right)$ & $\alpha$ \\
\hline M1 & 35.7 & 39 & 18.3 & 37.5 & 0.79 \\
\hline M2 & 43.8 & 42.5 & 26 & 41.5 & 0.76 \\
\hline M4 & 39.5 & 52 & 72.7 & 49 & 2.22 \\
\hline M5 & 32.3 & 64 & 83.6 & 60 & 4.13 \\
\hline M6 & 30.2 & 89 & 90.8 & 82 & 7.59 \\
\hline
\end{tabular}
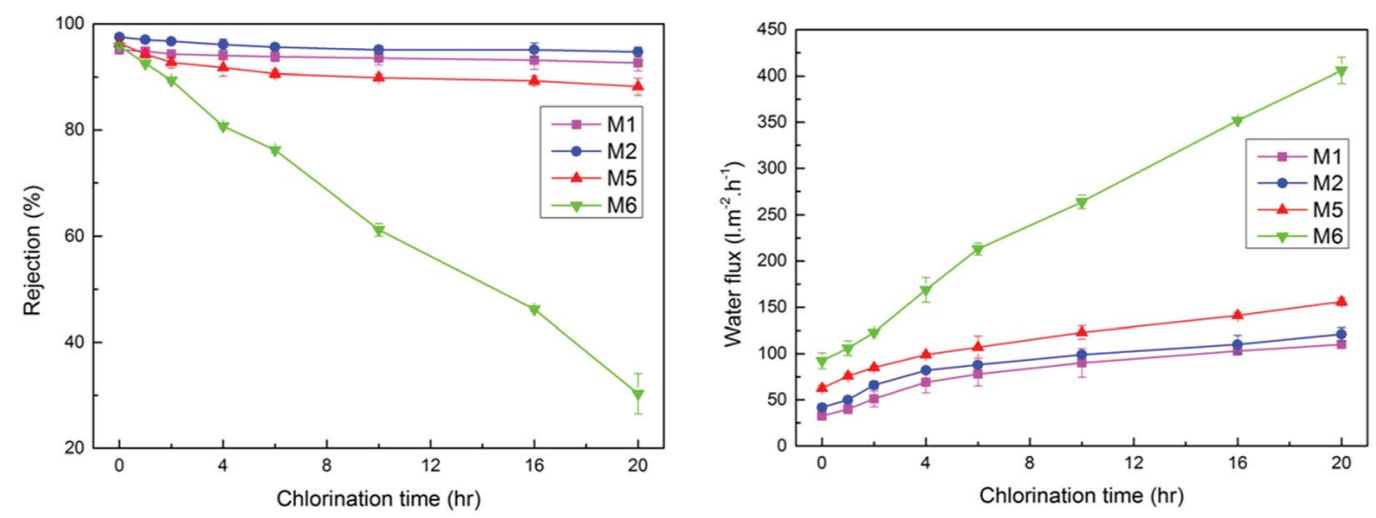

Fig. 8 Effect of chlorination time on separation performance of various NF membrane.

of the resulting "soft" active layer, the polymer chains collapse lead to a decreased water flux. ${ }^{15}$ To improve chlorine resistance, $m$-XDA is added into aqueous phase to react with TMC in this paper. The existence of $-\mathrm{CH}_{2}$ between $-\mathrm{NH}_{2}$ and benzene ring on the $m$-XDA monomer can reduce the activity of amide bonds and increase the steric hindrance. Further, $m$-XDA diffuses easily in the organic phase due to the small structure. Therefore, the top surface of just formed PA functional layer is dominated by $m$-XDA-TMC cross-linked network. The $m$-XDA-PEI crosslinking layer has good chlorine resistance which can protect the PEI-TMC cross-linked network inside PA functional layer. This is why the M2 and M5 prepared from a blend of $m$-XDA and PEI have good chlorine resistance while the M6 prepared from pure PEI has poor chlorine resistance.

\section{Conclusions}

In this paper, the NF membranes with excellent chlorine resistance and good separation performance were prepared by controlling the concentration ratio of $m$-XDA and PEI in the aqueous phase. Not only does it ensure that the rejection to $\mathrm{NaCl}$ and $\mathrm{Na}_{2} \mathrm{SO}_{4}$ of $\mathrm{NF}$ membrane retains substantially unchanged, but also increases the rejection to $\mathrm{MgCl}_{2}$ and $\mathrm{MgSO}_{4}$ of NF membrane, which can improve the rejection to $\mathrm{MgCl}_{2}$ and $\mathrm{MgSO}_{4}$ from $18.3 \%, 54.5 \%$ to $84.4 \%, 94.1 \%$, respectively. Meanwhile, the water flux of NF membrane can also increase from $32.5 \mathrm{~L} \mathrm{~m}^{-2} \mathrm{~h}^{-1}$ to $92.3 \mathrm{~L} \mathrm{~m}^{-2} \mathrm{~h}^{-1}$. After immersing in $500 \mathrm{ppm} \mathrm{NaClO}$ solution for various time, the rejection to $\mathrm{Na}_{2} \mathrm{SO}_{4}$ of all $\mathrm{NF}$ membrane decreased while the water flux increased. Particularly, the NF membranes prepared from $m$-XDA or mixture of $m$-XDA and PEI had good chlorine resistance while NF membrane prepared from pure PEI had poor chlorine resistance. It can be concluded that fabricating NF membranes by mixture of PEI and $m$-XDA is a promising way.

\section{Conflicts of interest}

There are no conflicts to declare.

\section{Acknowledgements}

This work was supported by the National Key Research and Development Program of China (Grant No. 2017YFC0403702).

\section{References}

1 R. Rautenbach and A. Gröschl, Separation potential of nanofiltration membranes, Desalination, 1990, 77(1-3), 7384.

2 S. Cheng, D. L. Oatley, P. M. Williams, et al., Positively charged nanofiltration membranes: review of current fabrication methods and introduction of a novel approach, Advances in Colloid \& Interface Science, 2011, 164(1), 12-20.

$3 \mathrm{~J}$. Lin, W. Ye, H. Zeng, et al., Fractionation of direct dyes and salts in aqueous solution using loose nanofiltration membranes, J. Membr. Sci., 2015, 477, 183-193.

4 P. Mobarakabad, A. R. Moghadassi and S. M. Hosseini, Fabrication and characterization of poly(phenylene etherether sulfone) based nanofiltration membranes modified 
by titanium dioxide nanoparticles for water desalination, Desalination, 2015, 365(3), 227-233.

5 B. M. Jun, H. K. Lee, Y. N. Kwon, et al., Acid-catalyzed hydrolysis of semi-aromatic polyamide NF membrane and its application to water softening and antibiotics enrichment, Chem. Eng. J., 2018, 332, 419-430.

6 P. G. Ingole, K. Singh and H. C. Bajaj, Enantioselective permeation of $\alpha$-amino acid isomers through polymer membrane containing chiral metal-Schiff base complexes, Desalination, 2011, 281(1), 413-421.

7 T. Tsuru, S. Sasaki, T. Kamada, et al., Multilayered polyamide membranes by spray-assisted 2-step interfacial polymerization for increased performance of trimesoyl chloride (TMC)/m-phenylenediamine (MPD)-derived polyamide membranes, J. Membr. Sci., 2013, 446(11), 504512.

8 M. N. A. Seman, M. Khayet and N. Hilal, Development of antifouling properties and performance of nanofiltration membranes modified by interfacial polymerisation, Desalination, 2011, 273(1), 36-47.

9 A. W. Mohammad, Y. H. Teow, W. L. Ang, et al., Nanofiltration membranes review: recent advances and future prospects, Desalination, 2015, 356, 226-254.

10 Y. Tang, B. Tang and P. Wu, Preparation of a positively charged nanofiltration membrane based on hydrophilichydrophobic transformation of a poly(ionic liquid), $J$. Mater. Chem. A, 2015, 3(23), 12367-12376.

11 B. W. Zhou, H. Z. Zhang, Z. L. Xu, et al., Interfacial polymerization on PES hollow fiber membranes using mixed diamines for nanofiltration removal of salts containing oxyanions and ferric ions, Desalination, 2016, 394, 176-184.

12 Q. Nan, P. Li and B. Cao, Fabrication of positively charged nanofiltration membrane via the layer-by-layer assembly of graphene oxide and polyethylenimine for desalination, Appl. Surf. Sci., 2016, 387, 521-528.

13 H. Z. Zhang, Z. L. Xu, H. Ding, et al., Positively charged capillary nanofiltration membrane with high rejection for $\mathrm{Mg}^{2+}$ and $\mathrm{Ca}^{2+}$ and good separation for $\mathrm{Mg}^{2+}$ and $\mathrm{Li}^{+}$, Desalination, 2017, 420, 158-166.

14 A. Bera, J. S. Trivedi, S. K. Jewrajka, et al., In situ manipulation of properties and performance of polyethyleneimine nanofiltration membranes by polyethylenimine-dextran conjugate, J. Membr. Sci., 2016, 519, 64-76.

15 Y. N. Kwon and J. O. Leckie, Hypochlorite degradation of crosslinked polyamide membranes: II changes in hydrogen bonding behavior and performance, J. Membr. Sci., 2006, 282(1-2), 456-464.

16 G. D. Kang, C. J. Gao, W. D. Chen, et al., Study on hypochlorite degradation of aromatic polyamide reverse osmosis membrane, J. Membr. Sci., 2007, 300(1), 165-171.

17 Y. J. Tang, Z. L. Xu, S. M. Xue, et al., A chlorine-tolerant nanofiltration membrane prepared by the mixed diamine monomers of PIP and BHTTM, J. Membr. Sci., 2016, 498, 374-384.
18 S. Lin, H. Huang, Y. Zeng, et al., Facile surface modification by aldehydes to enhance chlorine resistance of polyamide thin film composite membranes, J. Membr. Sci., 2016, 518, 40-49.

19 D. Hu, Z. L. Xu and Y. M. Wei, A high performance silicafluoropolyamide nanofiltration membrane prepared by interfacial polymerization, Sep. Purif. Technol., 2013, 110(5), 31-38.

20 H. Z. Zhang, Z. L. Xu, Y. J. Tang, et al., Highly chlorinetolerant performance of three-channel capillary nanofiltration membrane with inner skin layer, J. Membr. Sci., 2016, 527, 111-120.

21 W. Fang, L. Shi and R. Wang, Mixed polyamide-based composite nanofiltration hollow fiber membranes with improved low-pressure water softening capability, $J$. Membr. Sci., 2014, 468(20), 52-61.

22 D. Wu, S. Yu, D. Lawless, et al., Thin film composite nanofiltration membranes fabricated from polymeric amine polyethylenimine imbedded with monomeric amine piperazine for enhanced salt separations, React. Funct. Polym., 2015, 86, 168-183.

23 W. Xie, G. M. Geise, B. D. Freeman, et al., Polyamide interfacial composite membranes prepared from $\mathrm{m}$ phenylene diamine, trimesoyl chloride and a new disulfonated diamine, J. Membr. Sci., 2012, 403-404(6), 152-161.

24 S. Yu, M. Liu, Z. Lü, et al., Aromatic-cycloaliphatic polyamide thin-film composite membrane with improved chlorine resistance prepared from m-phenylenediamine-4-methyl and cyclohexane-1,3,5-tricarbonyl chloride, J. Membr. Sci., 2009, 344(1), 155-164.

25 T. Shintani, H. Matsuyama and N. Kurata, Development of a chlorine-resistant polyamide reverse osmosis membrane, Desalination, 2007, 207(1), 340-348.

26 P. S. Shi, T. A. Hatton, Y. C. Sui, et al., Novel thin-film composite nanofiltration hollow fiber membranes with double repulsion for effective removal of emerging organic matters from water, J. Membr. Sci., 2012, 401-402(10), 152162.

27 N. P. Soice, A. C. Maladono, D. Y. Takigawa, A. D. Norman, W. B. Krantz and A. R. Greenberg, Oxidative degradation of polyamide reverse osmosis membranes: studies of molecular model compounds and selected membranes, $J$. Appl. Polym. Sci., 2003, 90, 1173-1184.

28 C. Y. Tang, Y. N. Kwon and J. O. Leckie, Effect of membrane chemistry and coating layer on physiochemical properties of thin film composite polyamide RO and NF membranes: I FTIR and XPS characterization of polyamide and coating layer chemistry, Desalination, 2009, 242(1), 149-167.

29 O. Akin and F. Temelli, Probing the hydrophobicity of commercial reverse osmosis membranes produced by interfacial polymerization using contact angle, XPS, FTIR, FE-SEM and AFM, Desalination, 2011, 278(1-3), 387-396.

30 M. Morgenstern, T. Strasser, R. Adelung, et al., Contributions of the escape depth to the photoelectron intensity of a well-defined initial state, Phys. Rev. B: 
Condens. Matter Mater. Phys., 2004, 70(8), DOI: 10.1103/ physrevb.70.081305.

31 S. Bing, J. Wang, H. Xu, et al., Polyamide thin-film composite membrane modified with persulfate for improvement of perm-selectivity and chlorine-resistance, J. Membr. Sci., 2018, 318-326.

32 V. T. Do, C. Y. Y. Tang, M. Reinhard and J. O. Leckie, Degradation of Polyamide Nanofiltration and Reverse Osmosis Membranes by Hypochlorite, Environ. Sci. Technol., 2012, 46, 852-859.

33 D. Quéré, Wetting and Roughness, Annu. Rev. Mater. Res., 2008, 38(38), 71-99.

34 C. Y. Y. Tang, Y. N. Kwon and J. O. Leckie, Effect of membrane chemistry and coating layer on physiochemical properties of thin film composite polyamide RO and NF membranes II. Membrane physiochemical properties and their dependence on polyamide and coating layers, Desalination, 2009, 242, 168-182.

35 W. Z. Qiu, H. C. Yang, L. S. Wan, et al., Co-deposition of catechol/polyethyleneimine on porous membranes for efficient decolorization of dye water, J. Mater. Chem. A, 2015, 3(27), 14438-14444.

36 X. Y. Wei, Z. Wang, Z. Zhang, J. X. Wang and S. C. Wang, Surface modification of commercial aromatic polyamide reverse osmosis membranes by graft polymerization of 3- allyl-5,5-dimethylhydantoin, J. Membr. Sci., 2010, 351, 222233.

37 V. Freger, Kinetics of film formation by interfacial polycondensation, Langmuir, 2005, 21(5), 1884.

38 P. W. Morgan and S. L. Kwolek, Interfacial polycondensation II. Fundamentals of polymer formation at liquid interfaces, J. Polym. Sci., Part A: Polym. Chem., 1996, 34(4), 531-559.

39 G. Y. Chai and W. B. Krantz, Formation and characterization of polyamide membranes via interfacial polymerization, $J$. Membr. Sci., 1994, 93(2), 175-192.

$40 \mathrm{~W}$. R. Bowen and H. Mukhtar, Characterisation and prediction of separation performance of nanofiltration membranes, J. Membr. Sci., 1996, 112(2), 263-274.

41 A. W. Mohammad, N. Hilal, H. Al-Zoubi, et al., Prediction of permeate fluxes and rejections of highly concentrated salts in nanofiltration membranes, J. Membr. Sci., 2007, 289(12), 40-50.

42 V. T. Do, C. Y. Y. Tang, M. Reinhard and J. O. Leckie, Degradation of Polyamide Nanofiltration and Reverse Osmosis Membranes by Hypochlorite, Environ. Sci. Technol., 2012, 46, 852-859.

43 Y. N. Kwon and J. O. Leckie, Hypochlorite degradation of crosslinked polyamide membranes: I changes in chemical/ morphological properties, J. Membr. Sci., 2006, 283(1-2), 21-26. 